\title{
Chronic Application of NMDA Decreases the NMDA Sensitivity of the Evoked Tectal Potential in the Frog
}

\author{
E. A. Debskl, ${ }^{1}$ H. T. Cline ${ }^{1, a}$ J. W. McDonald, ${ }^{2, b}$ and M. ConstantIne-Paton ${ }^{1}$ \\ 'Department of Biology, New Haven, Connecticut 06511 and ${ }^{2}$ Neuroscience and Medical Scientists Training Program, \\ University of Michigan, Ann Arbor, Michigan 48109
}

The activity-dependent mechanism that refines the topography of the retinotectal projection in frogs is mediated by the NMDA receptor. Earlier studies found that chronic treatment of the optic tectum with the NMDA receptor antagonist DL-2-amino-5-phosphonovaleric acid (DL-AP5) desegregated eye-specific stripes in three-eyed frogs, while chronic treatment with NMDA sharpened stripe borders (Cline et al., 1987; Cline and Constantine-Paton, 1990). We now report that this same chronic treatment with NMDA decreases the electrophysiologically measured sensitivity of the optic tectum to applied NMDA: acute application of a given concentration of NMDA decreased the evoked tectal potential to a lesser extent in animals chronically treated with NMDA than it did in normal and sham-treated animals. This is observed as a shift to the right in the NMDA dose-response curves for both the positive and negative postsynaptic components of the evoked tectal response. We believe that this decreased NMDA receptor effectiveness further restricts the intermingling of axon branches from the two eyes by limiting synapse stabilization to areas where afferent activity is most correlated. This would account for the anatomical sharpening of stripe borders (i.e., increased afferent segregation). Quantitative autoradiographic analysis of ${ }^{3} \mathrm{H}$-glutamate binding to NMDA receptors indicated that binding densities within the tectum did not differ between control groups and NMDA chronically treated groups. We suggest that in the experimental animals the response to NMDA may be decreased by a change in the effectiveness of individual NMDA receptors rather than by decreases in receptor number. This experimentally induced change may be analogous to naturally occurring decreases in receptor function that correlate with the end of some periods of visual plasticity in mammals.

Topographic map formation requires a precise matching of presynaptic afferents to their postsynaptic targets. In the visual system this "matching" results in each point in visual space being represented at one location in the target. Furthermore, in order that the map maintain spatial relationships, neighboring

Received Nov. 12, 1990; revised Apr. 8, 1991; accepted May 8, 1991.

This work was supported by NIH Grants EY05818, EY05829, and EY06039.

Correspondence should be addressed to Elizabeth Debski, School of Biological

Sciences, University of Kentucky, 101 Morgan Building, Lexington, KY 40506.

a Present address: Department of Physiology and Biophysics, University of Iowa Medical School, Iowa City, IA 52242.

${ }^{b}$ Present address: Neuroscience Lab Building, 1103 East Huron Street, University of Michigan, Ann Arbor, MI 48104.

Copyright (C) 1991 Society for Neuroscience 0270-6474/91/112947-11\$03.00/0 points in visual space must be represented at neighboring points in the target structure. The processes by which topographic maps are formed have been studied extensively using the visual systems of Amphibia and fish (for reviews, see Udin and Fawcett, 1988; Constantine-Paton et al., 1990), where retinal ganglion cell axon arbors create maps of visual space at the optic tecta. This work has suggested that two processes lead to the formation of visual maps: a chemospecific process that roughly orders the projection and aligns it within the target zone (Sperry, 1963; Bonhoeffer and Huf, 1980; O'Rourke and Fraser, 1986; Walter et al., 1987; Vielmeyer and Steurmer, 1989) and an activitydependent process that establishes the point-to-point order of the projection (Law and Constantine-Paton, 1981; Whitelaw and Cowan, 1981; Meyer, 1982, 1983; Reh and ConstantinePaton, 1985).

The study of the chemospecific and activity-dependent processes that lead to topographic organization of the visual system has been facilitated by a preparation that anatomically assays the operation of these mechanisms. By implanting a third eye primordium into a tadpole embryo and forcing two afferent projections to share one tectal lobe, a series of alternating eyespecific afferent termination zones or stripes is created in the optic tectum (Constantine-Paton and Law, 1978; Law and Constantine-Paton, 1981). These stripes are the result of a compromise between the chemospecific process and the activity-dependent process, the former mechanism spreading each of the two projections across the surface of the tectum and the latter tending to keep each eye's projection separate from the other (Constantine-Paton, 1982). The disabling of the activity-dependent mechanism would cause a desegregation of stripes and an intermingling of the two projections.

Point-to-point ordering of the visual map in the frog is mediated, at least in part, by a subclass of glutamate receptors, the NMDA receptor: chronic treatment of the tecta of normal animals with the specific NMDA blocker DL-2-amino-5-phosphonovaleric acid (DL-AP5) dramatically decreases the fidelity of the normal retinotectal map (Cline and Constantine-Paton, 1989). Similar treatment of three-eyed animals results in the desegregation of the normal striped pattern (Cline et al., 1987). Treatment with NMDA receptor antagonists has also been shown to prevent both the alignment of binocular maps in Xenopus tectum (Scherer and Udin, 1989) and the fine tuning of the regenerated retinotectal projection in fish (Schmidt, 1990). These results have led to the idea that the ligand- and voltage-gating requirements for NMDA receptor/channel activation are satisfied by the correlated activity patterns of ganglion cells that neighbor one another in the retina. Ionic flux through the chan- 
nel then initiates the process leading to the stabilization of these synapses at neighboring synaptic sites (Cline et al., 1990; Constantine-Paton et al., 1990; Debski et al., 1990).

In contrast to the desegregation caused by chronic treatment with DL-AP5, chronic treatment with NMDA actually sharpens stripe boundaries (Cline et al., 1987; Cline and ConstantinePaton, 1990). This result was surprising because exogenous low levels of NMD $\Lambda$ might have been expected to result in stripe desegregation: continuous NMDA-induced depolarization of postsynaptic membranes would stabilize synapses even under poorly correlated conditions. Since this was the opposite of the observed result, we decided to investigate the state of these receptors in animals chronically treated with NMDA or AP5. We did this by comparing the decrease in the evoked tectal potential caused by acute NMDA application in treated animals to the decrease found in untreated and sham-treated animals. Binding studies were also performed to see if chronic treatment with either NMDA or AP5 resulted in a change in NMDA binding sites.

Some of these results have appeared in abstract form (Debski et al., 1989).

\section{Materials and Methods}

Rana pipiens tadpoles were raised from embryos in dilute Instant Ocean under daily conditions of approximately $12 \mathrm{hr}$ light/12 hr darkness. They were fed nettle in early stages of larval development and boiled romaine lettuce as tadpoles. Staging was done according to the criteria set forth by Taylor and Kollros (1946).

Surgery. Elvax plastic polymer (DuPont, Inc.) was infiltrated with a $10^{-4} \mathrm{M}$ concentration of either NMDA, DL-AP5, or L-AP5 (NMDA and DL-AP5 supplied by Sigma; L-AP5 supplied by Tocris Neuramin, UK; the amount of contamination of L-APV with $D$-APV is estimated at less than 3\%) as described in detail elsewhere (Silberstein and Daniel, 1982; Cline and Constantine-Paton, 1989). The Elvax was cut into thin slabs $(30 \mu \mathrm{m}$ thick $\times \approx 200 \mu \mathrm{m} \times 200 \mu \mathrm{m})$ on a cryostat for surgical implantation over the tecta of tadpoles. Stage $X$ animals were anesthetized by submersion in $0.05 \%$ ethyl $m$-amino benzoate (MS222; pH 7.4; Sigma). The dorsal surface of the optic tectal lobes of tadpoles was exposed by reflecting the overlying skin and cartilaginous skull. The dura was opened along the midline, and the arachnoid membrane was either lifted away from the tectal lobe in a sheet or peeled away to expose the surface of the tectal neuropil. The Elvax pieces, containing either NMDA, DL-AP5, or L-AP5, were laid over the tectal surface and held in place by the dural and/or arachnoid membranes. The brain covering and skin were replaced, and the wound was sealed with Histoacryl glue (Tri-Hawk, Montreal). Animals recovered from surgery in oxygenated dilute Instant Ocean supplemented with Penn/Strep (penicillin and streptomycin) (100 U/liter; Sigma). Recordings and receptor-binding studies were done 4-6 weeks later when the animals had reached stage XVIII-XIX. Investigation of the time course of relcase of substances from Elvax has shown that after an initial high discharge from the polymer lasting 5-6 d, approximately $0.3 \%$ of the drug concentration originally infiltrated is released daily for at least a period of $60 \mathrm{~d}$ (Cline and Constantine-Paton, 1989). The position of the Elvax was verified at the beginning of each physiology or binding experiment. Animals were not used if the Elvax could not be recovered over the dorsal tectum.

The physiological studies described below were conducted in parallel with complementary anatomical and receptor binding analyses of the effects of chronic drug treatment. Thus, after our inital finding on chronic AP5 and NMDA treatment (Cline et al., 1987), each group of animals exposed to the same drug-Elvax batch contributed data to both physiological and anatomical analyses. One of these groups treated with a batch of NMDA-Elvax that had been stored for more than 2 months at $4^{\circ} \mathrm{C}$ failed to show the anatomical effects of NMDA treatment observed in all other animals (Cline and Constantine-Paton, 1989, 1990). We concluded that the NMDA in this batch of Elvax had degraded, and the anatomical data obtained from this group was discarded. However, the evoked potential response to acutely applied NMDA was analyzed in three of these animals to control for the mechanical presence of the Elvax implant. These animals constituted the NMDA shamtreated group (see Table 1, Fig. 4).

Physiology. Physiology experiments utilized a tadpole preparation described in detail in Debski and Constantinc-Paton (1990). This preparation allows the stable recording of evoked tectal potentials from unanesthetized, nociceptor-isolated, in situ brain. Experiments were run on normal, untreated animals or animals chronically treated with NMDA, DL-AP5, or L-AP5. Briefly, animals were cannulated through the heart, having first been anesthetized with the short-lasting MS222. The spinal cord was removed and the trigeminal nerves cut to isolate the brain of the animal from noxious input. A second cannula replaced the spinal cord. Oxygenated, glucose-supplemented saline solution bathed the preparation through both of these cannulas. The dura was removed from one tectal lobe. The Elvax implant was usually situated just below the dura; it was removed, as well as some pial membrane centered directly under the Elvax. The resulting clear area of tectum constituted the recording site, marked on all sides by the remaining pial membrane. A bipolar stimulating electrode was inserted into the contralateral optic nerve at the base of the eye. Extracellular recording of the evoked tectal potential was accomplished with a tungsten electrode that had been plated with gold and then platinum. Previous work has shown that the amplitudes of the responses thus recorded change very little over the period of a recording session lasting several hours (Debski and Constantine-Paton, 1990).

The data presented in this article were recorded from sites approximately $100 \mu \mathrm{m}$ below the tectal surface. This is within the neuropil region where retinal afferents synapse with tectal dendrites. This depth was chosen because previous work demonstrated that it allowed recording of all three major postsynaptic responses (Fig. 1; Debski and Constantine-Paton, 1990). However, the small size and variability of the first of these components (the a wave) prohibited its use in the quantitative analysis of the effects of acute NMDA application reported here. Presynaptic activity in this preparation has been previously isolated and identified (Debski and Constantine-Paton, 1990). Because of the stratified nature of the tectum, this activity can only be seen at specific tectal recording sites. Short-latency presynaptic activity is not present in the recordings appearing in this article. Long-latency presynaptic activity is also not visible, although it may be present and masked by the much larger postsynaptic $b$ wave.

The optic nerve was stimulated 10 times at a rate of $0.1 / \mathrm{sec}$ at 15 min intervals. The evoked potential recorded for each time point consisted of the average of these 10 individual responses. In order to quantitate accurately the decline in the evoked potential with NMDA application (see below), we wished to start our experiments with a large response. Stimulus voltages were chosen such that they generated a "maximal" response for each preparation. In practice this meant that the stimulus voltage was increased until the evoked response amplitude remained constant when a stimulus $5 \mathrm{~V}$ greater in intensity was given. The former voltage was then used for the duration of the recording session. The voltages used were between 20 and $32 \mathrm{~V}$. The average voltage used for normal animals was $27 \pm 2 \mathrm{~V}( \pm \mathrm{SEM} ; N=7)$, and for DL-APV chronically treated animals, $29 \pm 1 \mathrm{~V}(N=8)$. The voltage used for all animals in the L-APV $(N=3)$, NMDA sham $(N=3)$, and NMDA chronically treated $(N=6)$ groups was $30 \mathrm{~V}$. The duration of the stimulus was $0.06 \mathrm{msec}$. Potentials were averaged on an RC Computerscope, digitized and analyzed by a Terak computer or acquired by a Rapid Systems Data Acquisition System $(2 \times 64)$, and analyzed using DADisp on an Epson Computer. Both methods of analysis yielded essentially identical results.

The protocol for the pharmacology experiments was the following: a control response was recorded, saline containing NMDA was introduced to the preparation, and 15 min later a response to the drug was recorded. Preliminary experiments indicated that a 10 min treatment with NMDA was sufficient to attain a stable evoked potential. The preparation was then returned to normal saline (the wash), and the amplitude of the response was checked at 15 and $30 \mathrm{~min}$. The position of the recording electrode remained unchanged throughout the experiment. In every case the wash reversed the effects of NMDA exposure. In most cases, NMDA decreased the response, and this meant that after washing the response increased and returned to the control values. However, in some cases, very low NMDA cxposurc was associatcd with an increased response (see Results), and washing actually decreased the size of response back to control values. Reversibility was defined by an evoked potential whose peak amplitude of the positive component (b wave) after washing was within $100 \mu \mathrm{V}$ of the control value. Using this criterion, the effect of NMDA under stable recording conditions was completely reversible 
Any incomplete reversibility was associated with electrode movement, and those data were discarded. Over all the animals used, both normal and implanted, the response after washing was an average of $99.5 \pm$ $1.4 \%$ ( $\pm \mathrm{SEM} ; N=78$ ) of the control response as judged by the peak amplitude of the $b$ wave. Individual values ranged from $69.7 \%$ to $137.6 \%$. Recovery in NMDA-implanted animals was not significantly different from recovery in normal animals. Following recovery, the sensitivity of the preparation to a different concentration of NMDA was tested.

Dose-response curves were constructed by calculating the area between baseline and the response for the two major postsynaptic components of the evoked potential [the $b$ and $c$ waves as defined previously (Debski and Constantine-Paton, 1990); see also Fig. 1]. The areas for the control and wash were then averaged, and the area of the response in NMDA was expressed as a percentage of these areas. This method of quantitating the NMDA effect allowed an accurate expression of the response recorded in NMDA as a percentage of the control response. The averaging procedure took into account the reversibility of the effect and the degree of baseline response variability. All $N$ values given represent the number of different animals used. In cases where application of a single NMDA concentration was tested several times in an individual preparation, the resulting analyzed data were averaged together, yielding a single value for the preparation. For example, although the sensitivity of L-APV-implanted animals to application of $6 \mu \mathrm{M}$ NMDA was tested a total of six times, the data were treated as $N=3$ because the testing occurred in only three different animals. All values are given as mean \pm SEM. A two-tailed Student's $t$ test was used to determine statistical significance. At concentrations of 12 and $16 \mu \mathrm{M}$ NMDA, the positive component was usually completely eliminated and the remaining response fell below baseline. In such cases, the area for the negative component was calculated starting from the point closest to baseline on what had been the positive component. At these doses, then, the area of the negative response was somewhat enlarged and included area before the beginning of the negative component seen in the control and wash conditions. The result is a slight but consistent overestimation of the amount of remaining $c$ wave at these NMDA concentrations or, in other words, a slight underestimation of the effect of applied NMDA. However, this would apply for both experimental and control groups of animals and should not affect the comparison between the doseresponse curves.

Receptor-binding studies. For receptor binding, the brains either of sham-operated animals (animals implanted with Elvax that did not contain any drug) or of animals chronically treated with NMDA, DLAP5, or L-AP5 were rapidly removed and frozen immediately on dry ice. Radiolabeling of NMDA and quisqualate-type receptors was performed on alternate frozen $20 \mu \mathrm{m}$ coronal sections. ${ }^{3} \mathrm{H}$-glutamate binding was carried out under two different conditions that sclect for NMDAand quisqualate-type binding sites (Greenamyre et al., 1985). For NMDA receptor binding, sections were preincubated for $30 \mathrm{~min}$ in ice-cold Trisacetate $(\mathrm{pH} \mathrm{7.4)}$ and dried. Sections were then incubated in ice-cold buffer with $40 \mathrm{nM}{ }^{3} \mathrm{H}$-L-glutamate (New England Nuclear) and $2.5 \mu \mathrm{M}$ quisqualate in the presence or absence of $1 \mathrm{~mm}$ glutamate. Sections were rapidly washed three times with $2 \mathrm{ml}$ ice-cold buffer, followed by a final $2 \mathrm{ml}$ rinse with a mixture of ice-cold glutaraldehyde and acetone $(1: 19$, $\mathrm{v} / \mathrm{v}$ ) and then rapidly dried. Quisqualate receptor binding was carried out in a similar manner except that the buffer used was Tris- $\mathrm{HCl}$ and the incubation buffer included $40 \mathrm{nM}^{3} \mathrm{H}$-L-glutamate plus $2.5 \mathrm{~mm} \mathrm{CaCl}_{2}$ and $100 \mu \mathrm{M}$ NMDA. Under these conditions, quisqualate-sensitive ${ }^{3} \mathrm{H}$ glutamate binding appears to represent binding to postsynaptic quisqualate receptors, rather than chloride-driven vesicular uptake or binding to 2-amino-4-phosphonobutyric acid (APB) receptors (Cha et al., 1988). Tissue sections were apposed to tritium-sensitive film (LKB Ultrofilm) for 2-8 weeks. A set of radioactive standards (ARC Tritium) calibrated against brain pastes of known amounts of tritium was exposed with each film. Quantitative densitometric analysis of the autoradiograms was performed using a microcomputer-based video densitometer system (Imaging Research, St. Catharines, Ontario). Optical density values were converted to $\mathrm{fmol} / \mathrm{mg}$ protein using a computer-generated polynomial regression analysis that compared film densities produced by the tissue sections to those produced by the radioactive standards (Pan et al., 1983). Five or more autoradiographic sections were analyzed per animal, and 10 readings were taken for each of the four areas studied; the pretectum and layers 5,6, and 9 in the dorsal tectum. Data represent specific binding (typically $>90 \%$ spccific binding). The Kruskal-Wallis nonparametric one-way ANOVA test was used to determine significance.

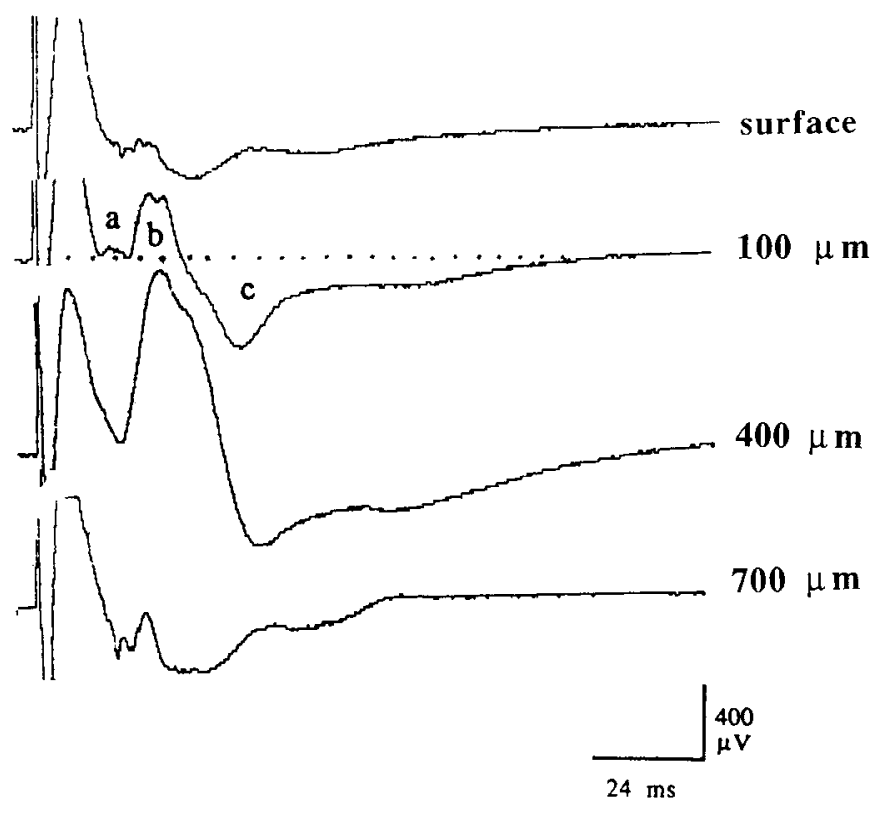

Figure 1. The extracellular response evoked by optic nerve stimulation as recorded at different depths within the tectum. Depths given at the right of the traces are approximate. Recordings in this article were taken from a depth of about $100 \mu \mathrm{m}$. The components of the response at that depth are a small positive wave ( $a$ wave), a large positive wave ( $b$ wave), and a large, long-lasting negative wave ( $c$ wave). The broken line represents baseline and was determined by the level of the recording immediately preceding the stimulus. Each response represents an average of 10 individual traces. This recording was taken from a stage $\mathrm{XX}$ tadpole. Data were taken from Debski and Constantine-Paton (1990).

\section{Results}

In response to electrical stimulation of the optic nerve, two major postsynaptic components are recorded within the optic tectum neuropil of the tadpole: a large positive component (b wave) and a large negative component (c wave; see Fig. 1). The relationship of these waves to the postsynaptic potentials recorded in the tectum of the adult animal by Chung et al. (1974) has been described in detail (Debski and Constantine-Paton, 1990). Briefly, comparison of polarity, time course, and latency indicates that the $b$ wave is made up of the last two of the four potentials they recorded, the $u_{1}$ and $u_{2}$ waves. The sizes of these potentials in the developing tadpole tectum are age dependent and are smaller than those recorded in the mature system. Chung et al. (1974) did not report a component corresponding to the long-latency, long-duration c wave in our recordings, although this component has been recorded by other investigators (Karamian et al., 1966; Nistri and Sivilotti, 1985). The c wave is composed of an early and a late component, with the late component being more prominent in some animals than in others (Debski and Constantine-Paton, 1990).

In normal tadpoles, perfusion with NMDA decreases the major postsynaptic components of the evoked potential. These decreases occur in a dose-dependent and completely reversible manner. Figure 2 illustrates the effect on the evoked potential of three different dose exposures to NMDA. Application of 2 $\mu_{\mathbf{M}}$ NMDA produced a small decline in the amplitude of the two major postsynaptic components: the $b$ and $c$ waves. As the dose of the applied NMDA was increased, progressively more of these postsynaptic components were eliminated. Exposure to $12 \mu \mathrm{M}$ NMDA eliminated most of the postsynaptic response. 


\begin{tabular}{|c|c|c|c|c|c|}
\hline & $\begin{array}{l}\text { Untreated } \\
(N=7)\end{array}$ & $\begin{array}{l}\text { NMDA } \\
\text { sham } \\
(N=3)\end{array}$ & $\begin{array}{l}\text { NMDA } \\
\text { implant } \\
(N=6)\end{array}$ & $\begin{array}{l}\text { DL-AP5 } \\
\text { implant } \\
(N=8)\end{array}$ & $\begin{array}{l}\text { L-AP5 } \\
\text { implant } \\
(N=3)\end{array}$ \\
\hline \multicolumn{6}{|c|}{ Peak amplitude $(\mu \mathrm{V})$} \\
\hline b wave & $546 \pm 75$ & $355 \pm 89$ & $284 \pm 27$ & $379 \pm 84$ & $374 \pm 41$ \\
\hline c wave & $300 \pm 33$ & $216 \pm 63$ & $253 \pm 29$ & $239 \pm 23$ & $150 \pm 7^{* * * *}$ \\
\hline \multicolumn{6}{|c|}{ Duration (msec) } \\
\hline b wave & $18.9 \pm 1.5$ & $17.0 \pm 1.7$ & $17.8 \pm 0.7$ & $17.3 \pm 3.2$ & $25.9 \pm 1.7^{*}$ \\
\hline c wave & $108 \pm 6.5$ & $97 \pm 19$ & $121 \pm 7.3$ & $128 \pm 6.8$ & $124 \pm 28$ \\
\hline \multicolumn{6}{|l|}{ Area } \\
\hline b wave & $545 \pm 101$ & $214 \pm 59$ & $231 \pm 37^{*}$ & $247 \pm 39 *, * * *$ & $550 \pm 74$ \\
\hline c wave & $1222 \pm 109$ & $745 \pm 328$ & $1333 \pm 133$ & $1127 \pm 154$ & $855 \pm 226$ \\
\hline
\end{tabular}

Values are given as means \pm SEM. $N$ represents individual preparations with response characteristics measured at the beginning of the experiment.

${ }^{*} p<0.05$ when compared to the value for the untreated animals; ${ }^{* *} p<0.05$ when compared to the value for the DLAP5-implanted animals; ${ }^{* * *} p<0.01$ when compared to the value for the L-AP5-implanted animals.

Most of these effects were reversible within 15 min after return to normal saline, and all were reversible within $30 \mathrm{~min}$.

No significant changes in the characteristics of the evoked response were specifically associated with chronic exposure to NMDA. Elvax implantation itself(NMDA sham animals) caused a reduction in the maximum amplitude and area of the $b$ and $c$ waves (Table 1). That is, chronic treatment with NMDA produced significant differences in the initial amplitude $(p<0.001$; $t=5.510 ; \mathrm{df}=11)$ and area $(p<0.02 ; t=2.733 ; \mathrm{df}=11)$ of the $b$ wave (recorded prior to acute NMDA application in drugfree saline) when compared to recordings done in untreated, stage-matched controls. However, the values for the NMDAtreated animals were no different from those recorded in the Elvax sham-treated animals. Chronic treatment with NMDA did not affect the peak amplitude, the area, or the duration of the $c$ wave.

Chronic treatment with the NMDA receptor antagonist AP5 also had no significant effect on evoked response characteristics. In DL-AP5 chronically treated animals, the area of the b wave was significantly decreased when compared to untreated animals $(p<0.05 ; t=2.900 ; \mathrm{df}=13$ ) but, again, it was no different from that in NMDA sham-treated animals. Presumably, then, this decrease is due to the implantation of the Elvax. The $c$ wave in animals chronically treated with DL-AP5 was indistinguishable in peak amplitude, area, or duration from that recorded in either untreated animals or sham animals. In contrast to the DL-AP5 results, chronic treatment with L-AP5 (an isomer of AP5 that is incffective in blocking NMDA receptors) increased the area of the $b$ wave to values found in untreated animals. This was achieved by an increase in the duration of this wave $(p<0.05 ; t=2.758$; df $=8)$. The $\mathrm{c}$ wave in L-AP5-treated animals was somewhat decreased in amplitude, but the area and duration of the wave remained near normal levels.

The ability of chronic treatment with L-AP5 to change components of the evoked response significantly was a somewhat surprising result since this isomer does not affect the NMDA receptor. However, L-AP5 has weak excitatory activity (Stone and Burton, 1988), and this may be the basis for the changes reported here. Increased excitation of the system may also underlie the changes in quisqualate binding caused by chronic L-AP5 treatment (see below).
Figure 3 is an example of the response of NMDA-implanted animals and DL-AP5-implanted animals to application of NMDA. The response of a normal animal is presented for comparison purposes. The effect of acute NMDA application was the same in animals previously treated chronically with NMDA or AP5 and in normal and sham-treated animals. That is, the postsynaptic components of the responses were reduced. The amount of reduction at different acute doses of NMDA was, however, different between normal or sham-treated animals and animals that had been chronically exposed to the drug. Compared to normal and sham groups, application of $6 \mu \mathrm{M}$ NMDA had less of an effect on both postsynaptic components of the NMDA-implanted animals. In contrast, AP5-implanted animals showed more of a reduction in the positive component of the response and about an equal effect on the negative component.

In order to quantitate this effect, dose-response curves of normal, NMDA-implanted, NMDA sham-treated, and AP5implanted animals were constructed (see Materials and Methods) and compared. Figure 4 presents the dose-response curves for the NMDA-implanted and normal animals. The $b$ and $c$ components of the response have been graphed separately. It can be seen that for normal animals application of NMDA decreased the positive component. This decrease occurred precipitously over a relatively narrow range of NMDA concentrations $(1-16 \mu \mathrm{M})$. At $12 \mu \mathrm{M}$ the elimination of the positive component was virtually complete. The same precipitous decline occurred with the ncgative component of the response, and again, doses of 12 and $16 \mu \mathrm{M}$ NMDA essentially eliminated the early peak component of this wave (see Fig. 2). However, unlike the $b$ wave, the area of the entire negative $c$ wave did not go to 0 but leveled off at about $40-45 \%$ of the control area. Some of this remaining area included area that was not counted when the $b$ wave was present (see Materials and Methods) as well as some negative area that was contributed by recording artifact that was not quantitatively separable from the response (Debski and Constantine-Paton, 1990). Nevertheless, a response that was low in amplitude and long in duration remained in these animals, indicating that the entire negative component was more resistant to complete elimination than was the positive one. The dose-response curves for the NMDA sham-treated animals were 

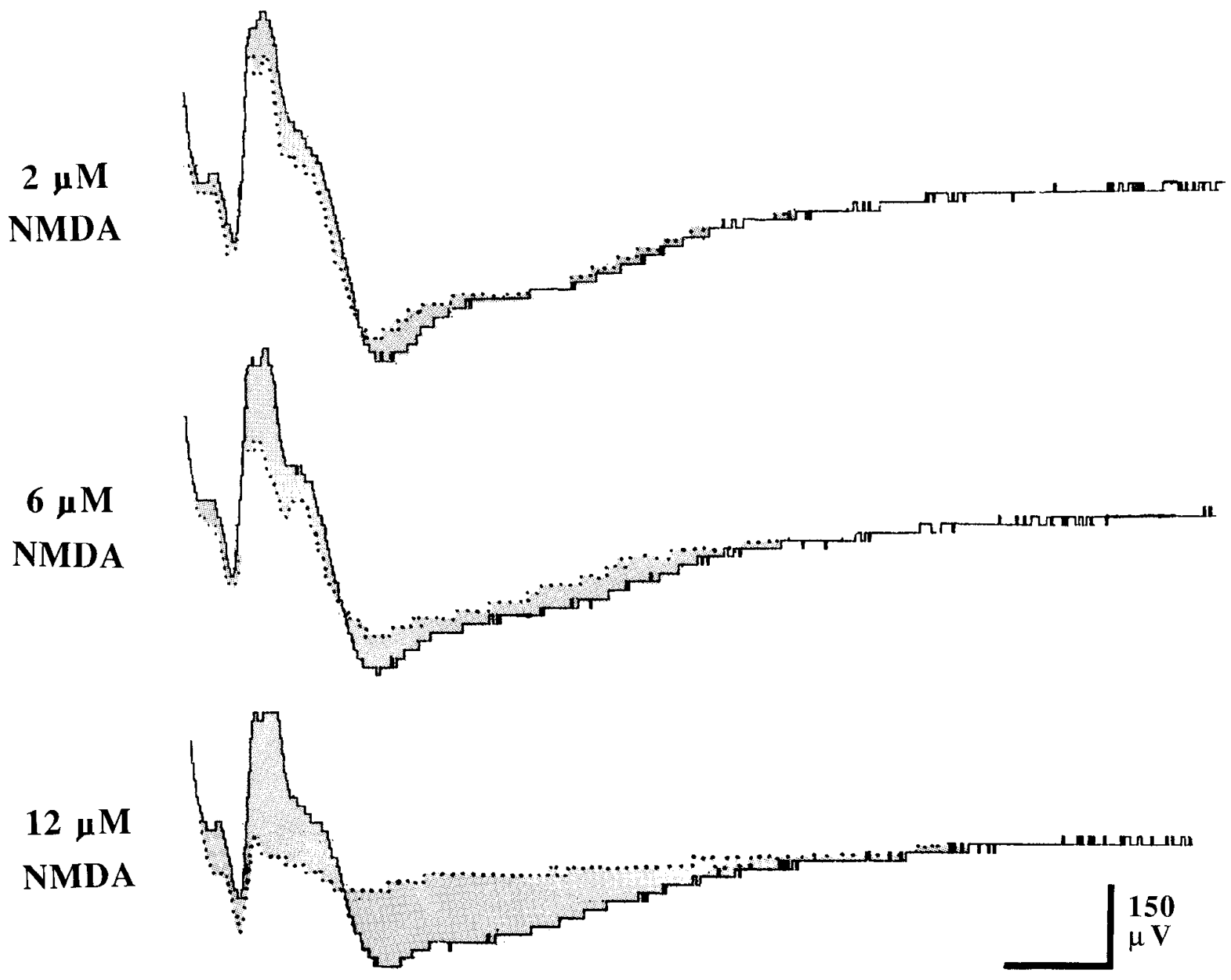

$16 \mathrm{~ms}$

Figure 2. Example of the effect of NMDA on the evoked tectal potential in a normal animal. The response in NMDA (broken line) has been superimposed on the control response (response in normal saline before NMDA exposure; solid line) for three different concentrations of NMDA. The shaded area represents the difference between the traces under the two recording conditions. Traces represent successive responses to NMDA exposure at a single tectal site. Acute application of NMDA decreased the postsynaptic components of the response in a dose-dependent manner. Exposure to $12 \mu \mathrm{M}$ NMDA eliminated most of the $\mathrm{a}, \mathrm{b}$, and $\mathrm{c}$ waves. Wash responses are not presented, but their peak amplitudes were within $100 \mu \mathrm{V}$ of the control responses. All recordings were made approximately $100 \mu \mathrm{m}$ below the tectal surface.

virtually indistinguishable from those of the normal animals.

As can be seen in Figure 4, the dose-response curves of NMDAimplanted animals were shifted to the right of those for the normal and sham groups. This was true for both the positive and negative components of the response. The effect of applied NMDA on the $b$ wave of NMDA chronically treated animals at NMDA concentrations of both 6 and $12 \mu \mathrm{M}$ was significantly different from that of the combined group of normal and shamtreated animals (Fig. $4 A ; 6 \mu \mathrm{M}: p<0.001, t=7.36$, $\mathrm{df}=9 ; 12$ $\mu \mathrm{M}: p<0.01, t=3.33$, df $=9$ ). Thus, the $\mathrm{b}$ wave in animals chronically treated with NMDA had a decreased sensitivity to applied NMDA.

The $\mathrm{c}$ wave also showed a decreased sensitivity to applied NMDA in the animals chronically treated with the drug: $6 \mu \mathrm{M}$ and $12 \mu \mathrm{M}$ produced effects that were significantly different from those produced in the combined normal and sham-treated group (Fig. $4 B ; 6 \mu \mathrm{M}: p<0.02, t=3.15$, df $=9 ; 12 \mu \mathrm{M}: p<0.001, t$ $=6.18$, df =9). At $16 \mu \mathrm{M}$, the points for each component were not significantly different in any of the three groups of animals. The dose-response curves indicated that the same amount of decrease in the evoked response as seen in normal and shamtreated animals was possible in the NMDA-implanted animals; the animals chronically treated with NMDA simply required a higher dose of applied NMDA to produce that same decrease.

It is interesting to note that at very low NMDA concentrations $([\mathrm{NMDA}] \leq 1 \mu \mathrm{M})$ application of NMDA actually increased the size of evoked response in some but not all of the animals. It is for this reason that the curves for the $b$ wave as well as the c wave start somewhat above $100 \%$. This increase may simply be a consequence of a small amount of variation in response amplitude.

The physiological effects of chronic treatment with DL-AP5Elvax and L-AP5-Elvax implants were also examined. Chronic treatment with either DL-AP5 or L-AP5 had no detectable effect on the decline of the negative component produced by NMDA application (Fig. 5B). The threshold at which NMDA decreased 
A) UNTREATED
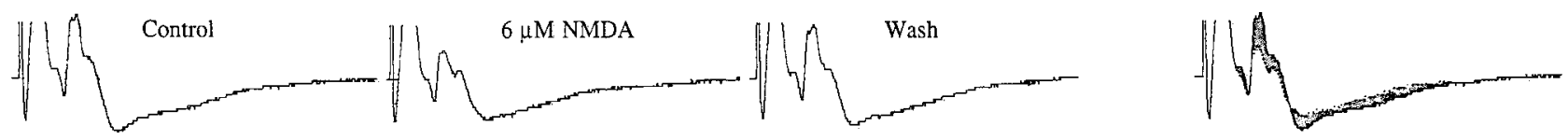

B) NMDA IMPLANT
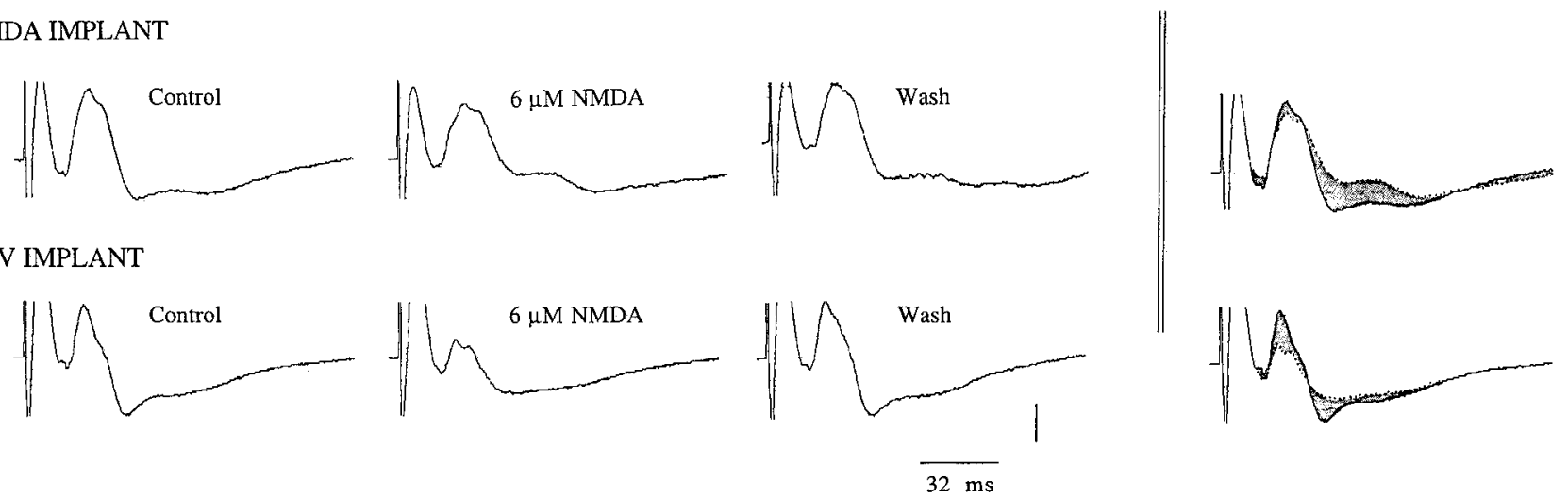

C) APV IMPLANT
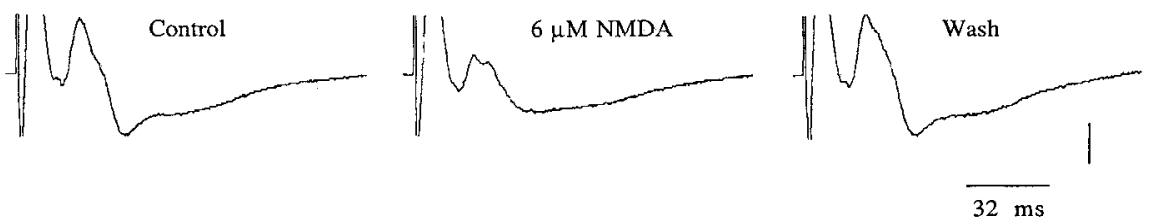

Figure 3. Effect of perfusion of $6 \mu \mathrm{M}$ NMDA on normal and implanted animals. For each animal the responses before NMDA application (control), during NMDA application, and $15 \mathrm{~min}$ after return to normal saline solution (wash) are presented. In the far right column are superimposed the control response (solid line) and response in NMDA (broken line), with the difference between the curves shown with shading. $A$, Normal animal. NMDA perfusion reduced the response by approximately half. $B$, Animal chronically treated with NMDA for 6 weeks before the recording session. Most of the response remained with NMDA perfusion. $C$, Animal chronically treated with DL-AP5 for 6 weeks before the recording session. Only about one-fourth of the positive component remained. However, approximately $60 \%$ of the negative component remained. Vertical scale: $A, 400$ $\mu \mathrm{V} ; B$ and $C, 200 \mu \mathrm{V}$.

the positive component was also the same in all three groups of animals $(\approx 1 \mu \mathrm{M})$. However, the positive component appeared to decline faster in DL-AP5-treated animals than in normal or L-APV-treated ones: $6 \mu \mathrm{M}$ NMDA applied to the animals chronically treated with NMDA produced a point significantly below the point for normal animals $(p<0.05 ; t=2.858$; df $=5$ ) and for L-APV-treated animals ( $p<0.01 ; t=3.39$; df $=5$ ).

\section{Receptor binding studies}

The tectum is divided into nine layers based on morphological criteria (Székely and Lázár, 1976). The layers are numbered sequentially with layer 1 abutting the ventricle and layer 9 being located most superficially. Previous work describing the distribution of NMDA and quisqualate binding sites in the tecta of normal and three-eyed tadpoles has shown that layer 9 , the retinotectal synaptic zone, has the highest density of both of these binding sites (McDonald et al., 1989). In contrast, the least amount of binding was seen in layer 6 , the predominant cell body layer. We looked for a change in NMDA or quisqualate binding induced by chronic NMDA or AP5 treatments in tectal layers 6,9 , and 5 (a plexiform layer that does not contain any cell bodies) and in a region outside of the tectum, the pretectum (Fite and Scalia, 1976; McDonald et al., 1989).

As can be seen in Table 2, sham-operated two-eyed animals have many more NMDA and quisqualate binding sites in layer 9 as opposed to layer 6 . Chronic 4-6 week treatments of optic tecta of tadpoles with the NMDA receptor antagonist DL-AP5 or with the NMDA receptor agonist NMDA did not significantly alter specific ${ }^{3} \mathrm{H}$-glutamate binding to either NMDA or quisqualate sites in any tectal layer tested. However, two significant effects of chronic treatment were observed: L-AP5 treatment increased quisqualate binding in layer 9 (Table 2), and treatment of tecta with NMDA increased NMDA receptor binding in the pretectum, from $1074 \pm 71 \mathrm{fmol} / \mathrm{mg}$ protein in untreated brains to $1383 \pm 118 \mathrm{fmol} / \mathrm{mg}$ protein in NMDA-treated brains $(p<$ $0.001)$. The pretectum is an area that has a high density of quisqualate and NMDA binding sites (McDonald et al., 1989) and receives retinal ganglion and tectal cell input (Fite and Scalia, 1976); it is also not in contact with the Elvax implant. Therefore, it is likely that the changes in NMDA binding in this area are produced as a consequence of implant-related changes in tectal input. The increase in quisqualate binding in layer 9 of the tectum with L-APV treatment is, however, somewhat surprising. Acute treatment with L-APV has no effect on the size of the extracellular potential evoked by optic nerve stimulation (E. A. Debski, unpublished observations). Nevertheless, in other systems, this isomer has been reported both to depress synaptic activity (Collingridge et al., 1983) and to have weak excitatory effects (Stone and Burton, 1988).

\section{Discussion}

\section{NMDA receptor effectiveness}

Retinotectal transmission in the frog can be blocked by application of a general glutamate receptor antagonist, indicating that glutamate is used as a neurotransmitter by retinal ganglion cells (Debski et al., 1987; Debski and Constantine-Paton, 1988). The reason why acute NMDA application in both normal and chronically treated animals causes a decrease of the evoked postsynaptic components is under investigation. Patch-clamped tectal neurons have APV-sensitive currents (Hickmott and Constantine-Paton, 1990). This demonstrates that NMDA receptors are located on many tectal cell membranes, yet one possibility for the decline in the postsynaptic potential with NMDA application is that some NMDA receptors are also located on the retinal afferents. The applied NMDA would then cause the depolarization of these afferents and the shunting of the electrically 


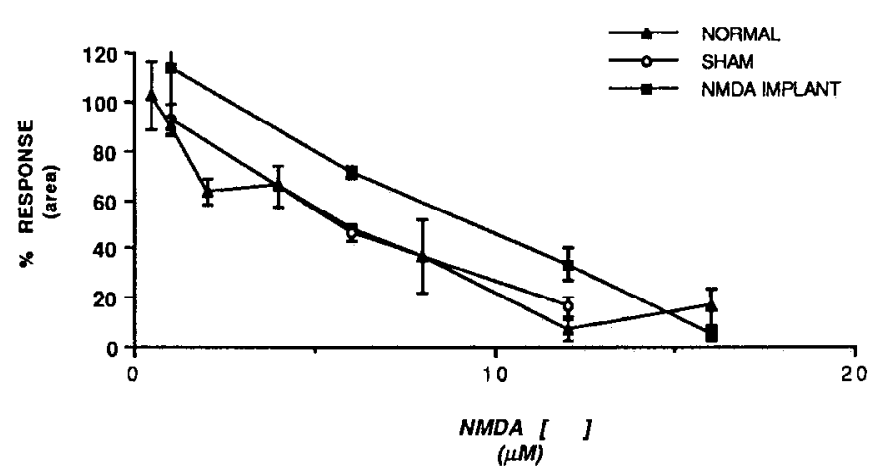

B) NEGATIVE COMPONENT (C WAVE)

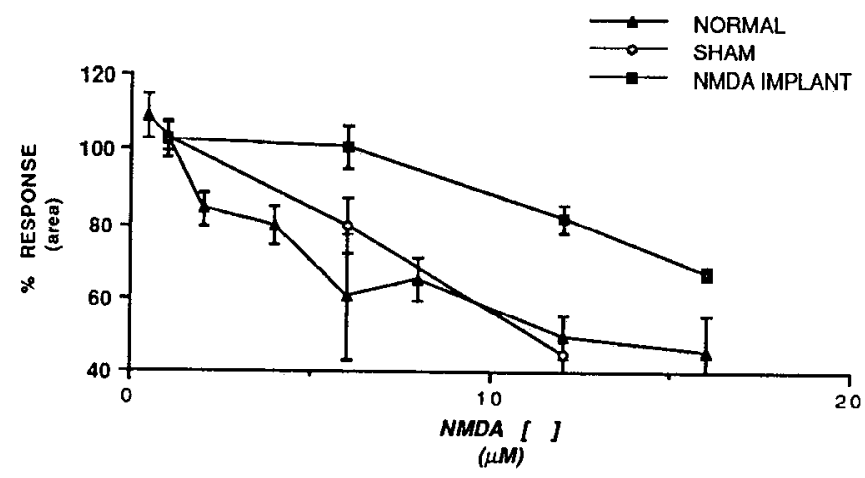

Figure 4. NMDA dose-response curves for normal, sham-treated, and NMDA chronically treated animals. The ordinate is the area of the response remaining in the drug as a percentage of the mean of the control and wash areas (see Materials and Methods). The two major components of the postsynaptic evoked potential have been graphed separately. $A$, Large positive component of the response. $B$, Large negative component of the response. The dose-response curves for the normal and NMDA sham-treated animals are indistinguishable from one another. The curves for the NMDA-implanted animals are significantly above those for the normal and NMDA sham animals for both the positive component (b wave) and the negative component ( $c$ wave). This indicates that the animals chronically treated with NMDA had a decreased sensitivity to applied NMDA. Solid triangles, normal animals $(N=3,3,3,4,3,4$, 4 , and 5 for $0.5,1,2,4,6,8,12$, and $16 \mu \mathrm{M}$, respectively); open circles, NMDA sham-treated animals $(N=3,3$, and 3 for 1,6 , and $12 \mu \mathrm{M}$, respectively); solid squares, NMDA-implanted animals $(N=4,5,4$, and 2 for 1, 6, 12, and $16 \mu \mathrm{M}$, respectively). Error bars represent SEM.

evoked signal. It is also possible that the postsynaptic NMDA receptors are being desensitized by the exogenous NMDA and are unable to respond to the electrical stimulation of the optic nerve. However, these interpretations of the data appear inconsistent with the increase in background activity obtained during application of NMDA to the cannulated tadpole preparation (E.A. Debski, unpublished observations). Another possibility is that NMDA receptors are concentrated on inhibitory cells. These cells, when driven by exogenous NMDA, may actually shut down the evoked tectal response. A final possibility is that the NMDA, by increasing the spontaneous activity of tectal cells, maintains a significant proportion of them in depolarization block or with low membrane impedance, and they are therefore unable to respond to stimulus-evoked release of transmitter
A) POSitive component (B WAVE)

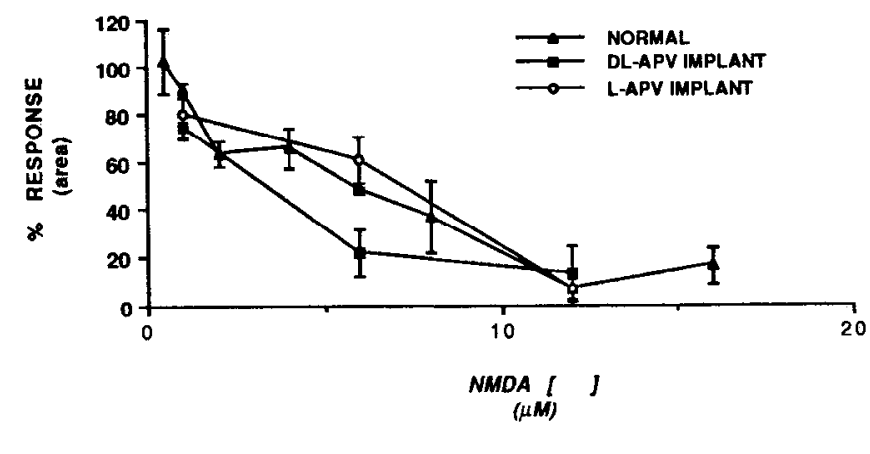

B) NegATIVE COMPONENT (C WAVE)

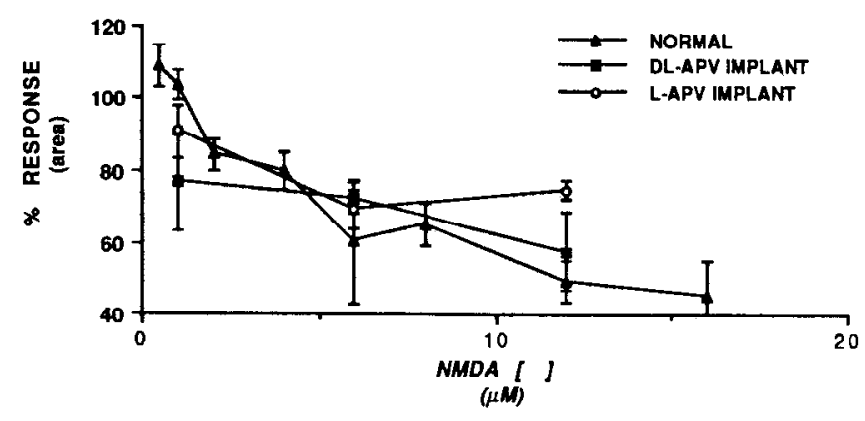

Figure 5. NMDA dose-response curves for normal animals and animals chronically treated with either DL-APV or L-APV. The two major components of the postsynaptic response have been graphed separately. $A$, Large positive component of the response. The curve for the DLAP5-implanted animals lies below that for the normal and L-APV animals. $B$, Large negative component of the response. There are no discernible differences in the curves for the three groups of animals. Solid triangles, normal animals ( $N$ values are given in Fig. 4 caption); solid squares, DL-APV-implanted animals $(N=3,4$, and 3 for 1,6 , and 12 $\mu \mathrm{M}$, respectively); open circles, L-APV-implanted animals $(N=3,3$, and 3 for 1,6 , and $12 \mu \mathrm{M}$, respectively). The dose-response curves for normal animals, presented in Figure 4, have been replotted here for comparison. Error bars represent SEM.

from optic nerve terminals. None of these possibilities are mutually exclusive. Regardless of the reason underlying these effects, analysis of the evoked tectal potential provides a highly reliable, stable measure of the responsiveness of the system to application of small quantities of NMDA. It therefore represents a useful tool for assaying changes in NMDA receptor effectiveness in the developing tectum.

We have demonstrated that in tecta chronically treated with NMDA, the components of the tectal response evoked by optic nerve stimulation have a decreased sensitivity to applied NMDA. The decreased sensitivity to NMDA that we found is a longterm change and therefore different from the rapid desensitization reported by others (Trussell et al., 1988; Mayer et al., 1989). There are five distinct ways in which a change of the NMDA receptor system could lead to a decreased responsiveness of the preparation to NMDA: (1) by a change in the number of NMDA receptors, (2) through a modification of the NMDA receptor/channel that reduces the ionic flux through the channel 
2954 Debski et al. • Chronic NMDA Treatment Decreases NMDA Sensitivity

Table 2. Specific binding of ${ }^{3} \mathrm{H}$-glutamate to NMDA and quisqualate sites in untreated (sham-operated) and drug-treated tadpole brains

\begin{tabular}{|c|c|c|c|c|c|c|c|c|}
\hline & \multicolumn{8}{|c|}{ Ligand bound (fmol/mg protein) } \\
\hline & \multicolumn{2}{|c|}{ Layer 9} & \multicolumn{2}{|l|}{ Layer 6} & \multicolumn{2}{|l|}{ Layer 5} & \multicolumn{2}{|l|}{ Pretectum } \\
\hline & NMDA & Quisqualate & NMDA & $\overline{\text { Quisqualate }}$ & NMDA & Quisqualate & NMDA & Quisqualate \\
\hline Control & $673 \pm 37$ & $542 \pm 50$ & $60 \pm 15$ & $237 \pm 27$ & $227 \pm 40$ & $330 \pm 32$ & $1074 \pm 71$ & $2005 \pm 77$ \\
\hline NMDA & $745 \pm 19$ & $524 \pm 14$ & $43 \pm 11$ & $184 \pm 13$ & $262 \pm 31$ & $324 \pm 31$ & $1383 \pm 118^{* *}$ & $2178 \pm 245$ \\
\hline DL-AP5 & $565 \pm 65$ & $530 \pm 11$ & $51 \pm 17$ & $220 \pm 20$ & $179 \pm 25$ & $348 \pm 24$ & $1055 \pm 54$ & $2041 \pm 178$ \\
\hline L-AP5 & $682 \pm 41$ & $857 \pm 86^{*}$ & $50 \pm 5$ & $273 \pm 69$ & $301 \pm 55$ & $452 \pm 65$ & $1092 \pm 57$ & $1888 \pm 150$ \\
\hline
\end{tabular}

Values represent the mean and SEM of four or five animals per group.

${ }^{*} p<0.002$ between DL-AP5 and L-AP5.

${ }^{* *} p<0.001$ between NMDA and control.

[such a change could occur at any of the regulatory sites now described for this receptor (Mayer et al., 1984; Nowak et al., 1984; Johnson and Ascher, 1987; Reynolds et al., 1988; Sah, 1988; MacDonald et al., 1989)], (3) by a redistribution of NMDA receptors, (4) by a change within the cells expressing NMDA receptor/channels such that the same ion influx is less effective, or (5) through a change in the balance of inhibitory versus excitatory inputs within the tectum.

There is some precedence for acute or chronic treatment with an NMDA antagonist leading to an increase in the number of NMDA binding sites. Treatment with MK-801, a noncompetitive NMDA antagonist, increases ${ }^{3} \mathrm{H}$-glutamate binding at NMDA-preferring recognition sites in perinatal rats (McDonald et al., 1990b). Interestingly, it does so without altering glycine or phencyclidine (PCP) binding (Uckele et al., 1989). However, no such changes in NMDA recognition sites have been reported for chronic treatment with an agonist, and we found no evidence for such a change using standard NMDA receptor binding techniques. It is possible that the change may be so small as to be beyond the resolution of our techniques. Nevertheless, these same methods were sufficiently sensitive to detect a consistent change in the pretectal nucleus to applied NMDA. Thus, absence of changes in receptor-binding characteristics in the tectum suggests that the decrease in NMDA effectiveness found in NMDA chronically treated animals has as its basis one of the other three possibilities, each of which need not result in a change in the number of NMDA binding sites.

\section{Synapse stabilization and stripe sharpening}

Our studies suggest that the NMDA receptor plays a role in the establishment of the visual projection by selectively stabilizing synapses from ganglion cells that are retinal neighbors (Cline and Constantine-Paton, 1989, 1990; Cline et al., 1990). Considerable data in frogs (Roberts and Yates, 1976; Debski et al., 1987; Fox and Fraser, 1987) as well as other animals (Cuénod and Streit, 1979; Langdon and Freeman, 1986) indicate that the retinal projection to the tectum is glutamatergic. In addition, it is known that ganglion cells that neighbor one another have correlated activity patterns (Arnett, 1978; Arnett and Spraker, 1981; Mastronarde, 1983a,b; Ginsberg et al., 1984). These correlated patterns of firing would be sufficient to satisfy the requirements for NMDA activation: binding of ligand during membrane depolarization. Thus, when neighboring retinal afferents converge onto the same tectal cell, their correlated activity patterns will activate NMDA receptors and allow calcium into the cell. Calcium entry could act to stabilize the synapses that were just active. Synapses from ganglion cells that do not neighbor one another in the tectum do not have well-correlated activity patterns and therefore will not elevate intracellular calcium through activation of the NMDA receptor to the levels required to effect synapse stabilization (Cline et al., 1987; Constantine-Paton et al., 1990).

Within this framework, it is possible to understand how decreased effectiveness of NMDA receptors in animals chronically treated with NMDA could underlie the sharpening of the eyespecific segregation seen in striped tecta. In normal animals with high NMDA receptor responsiveness, a high degree of correlated activity is proportional to a high probability of synapse stabilization. In animals with decreased effectiveness of NMDA receptors, this same amount of correlated activity is proportional to a much lower probability of synapse stabilization (Fig. 6). Thus, decreased receptor effectiveness would restrict synapse stabilization to areas where activity is most correlated. Stripe borders are regions where uncorrelated synapses from the two eyes mix. Consequently, they represent areas where the correlation between converging synapses is low. Synapses that in untreated animals could be stabilized fall below the threshold for synapse stabilization after chronic NMDA treatment. The terminal end branches that do not have stabilized synapses on them would also be withdrawn. The result is a decrease in the intermingling of axonal branches from different eye-specific zones or what is seen in the morphological assay as an increase in the sharpness of the boundary between the stripes and a decreased arborization density of single retinal ganglion cell terminals (Cline and Constantine-Paton, 1990).

Our data indicate that the physiological effectiveness and the synapse stabilizing ability of NMDA receptor activation may be regulated in the absence of any change in the number of NMDA receptors. We suggest that we may be experimentally triggering a system for controlling NMDA receptor effectiveness that is normally required to deal with changing convergent inputs within an extended period of developmental plasticity. In the tadpole, retinotectal synapses are constantly being formed and broken to retain retinotopy as the system adjusts to the disparate growth patterns of the retina and the optic tectum (Reh and Constantine-Paton, 1984). During this period, the mechanism that fine-tunes the topographic projection must be in continuous operation, yet the spatial resolution of the map and therefore the degree of correlated activity per unit volume of neuropil appears to be changing: the proportion of tectum covered by a single, embryonic retinal ganglion cell terminal is much larger than the proportion of tectum covered by adult 
A)

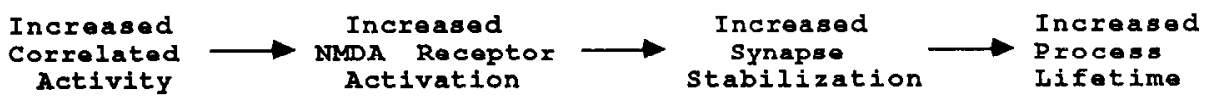

B)

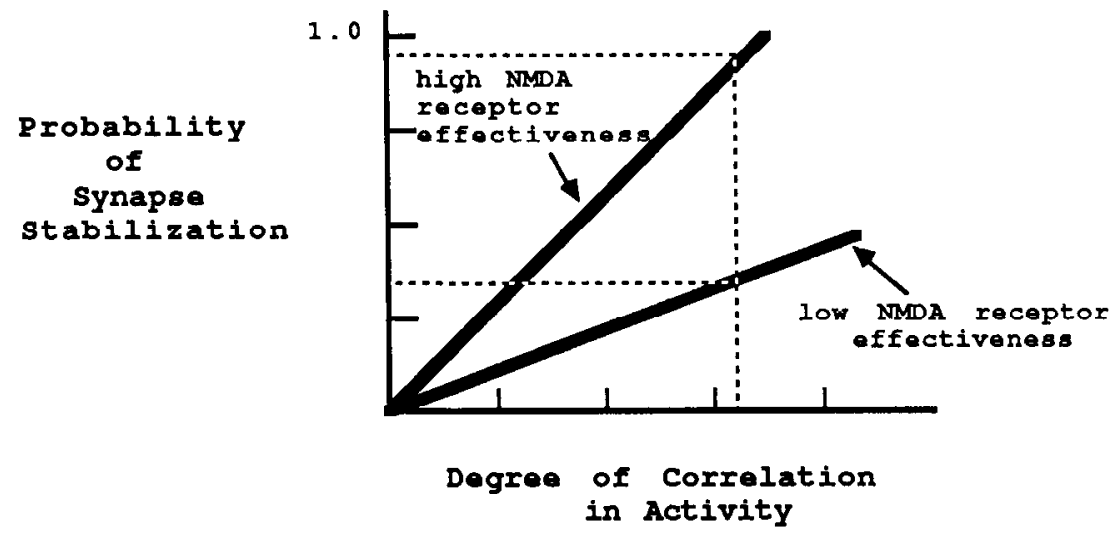

Figure 6. $A$, Flow diagram of proposed relationships between correlated activity, NMDA receptor activation, synapse stabilization, and the lifetime of a process or end terminal. $B$, Diagrammatic representation of the relationship between the amount of correlated activity, NMDA receptor effectiveness, and the probability of synapse stabilization. Animals with a low NMDA receptor effectiveness have a lower probability of synapse stabilization for a given amount of correlated activity. Curves shown for NMDA receptor effectiveness are hypothetical.

arbors (Sakaguchi and Murphey, 1985; Stuermer, 1988; Cline and Constantine-Paton, 1990). It may be that while the map is being refined, the effectiveness of the tectal NMDA receptors/ channels (Hickmott and Constantine-Paton, 1990) is changing. In this situation, a feedback system in which NMDA receptor effectiveness on young neurons is downregulated in response to increased activation would constitute a highly adaptive mechanism to minimize neurotoxic damage produced by excessive calcium influx. Such a change could simultaneously decrease the effectiveness of the synapse stabilization cascade. The result would be that more stringently correlated inputs are required to stabilize synapses and that synapses are "pruned" from regions of poorly correlated activity.

This explanation for our data suggests a general role for the NMDA receptor in defining critical periods for developmental plasticity. In the developing cat visual cortex, the onset of visual plasticity is characterized by a relatively high density of NMDA binding sites (Bode-Greuel and Singer, 1989) and a high degree of NMDA receptor sensitivity of neurons in layer IV (Fox et al., 1989b). High numbers of NMDA receptors may facilitate major movements of axon arbors since they represent potential sites at which synapses may be easily stabilized. A high density of such sites would allow for a sorting and shifting period of synaptogenesis in the target that would ultimately optimize the degree of activity correlation among converging synaptic neighbors.

The end of some critical periods for developmental plasticity correlates more closely with a decrease in the NMDA receptor component of the response than with a decrease in NMDA binding sites. In close accord with the findings presented here, physiologically measured declines in the NMDA receptor potency of layer IV cells in the cat visual cortex are correlated with the end of geniculocortical afferent segregation that occurs between the third and fourth week after birth (LeVay et al., 1978; Fox et al., 1989b). In contrast, NMDA binding sites, having increased from their initial low 2 week values, remain steady at their high 4 week levels to at least 12 weeks (Bode-Greuel and Singer, 1989). During this period of high NMDA binding, kittens are becoming increasingly less sensitive to monocular deprivation paradigms (Cynader, 1982; Fox et al., 1989a). Rearing kittens in the dark, which prolongs the critical period ( $\mathrm{Cy}$ nader, 1983), does not delay the decrease in NMDA binding sites (Bode-Greuel and Singer, 1989). Dark-rearing does, however, prevent the decline in the NMDA receptor potency (Fox et al., 1991). In short, in the visual system of both mammals and frogs the NMDA receptor seems to be a permissive factor: these receptors must be present during periods of synaptic plasticity, but changes either in their function or in the translation of function to structural changes in arbor morphology regulate the amount of visual plasticity that will occur.

\section{Conclusions}

Chronic treatment with NMDA causes a change in the placement of axon branches such that stripe borders in three-eyed animals become sharper (Cline et al., 1987; Cline and Constantine-Paton, 1990). The work presented here demonstrates that this same treatment decreases the sensitivity of the same groups of animals to acutely applied NMDA for periods at least as long as the 6-8 hr required to run an experiment. To our knowledge, this is the first experimental evidence in which a structural measure of plasticity has been correlated with a change in NMDA receptor responsiveness. If indeed NMDA receptor activation underlies many kinds of plasticity as has been suggested (Bear et al., 1987; Collingridge and Bliss, 1987; Gustafsson and Wigstrom, 1988; Constantine-Paton et al., 1990; McDonald and Johnston, 1990a), then the demonstration that changes in NMDA receptor-based physiology are correlated with changes in ccllular morphology is likely to have broad significance to studies of both developmental and mature brain plasticity.

\section{References}

Arnett DW (1978) Statistical dependence between neighboring retinal ganglion cells in goldfish. Exp Brain Res 32:49-53.

Arnett DW, Spraker TE (1981) Cross-correlation analysis of the maintained discharge of rabbit retinal ganglion cells. J Physiol (Lond) 317 : $29-47$. 
Bear MF, Cooper LN, Ebner FF (1987) A physiological basis for a theory of synapse modification. Science $237: 42-48$.

Bode-Greuel K, Singer W (1989) The development of $N$-methyl-Daspartate receptors in cat visual cortex. Dev Brain Res 46:197-204.

Bonhoeffer F, Huf J (1980) Recognition of cell types by axonal growth cones in vitro. Nature 288:162-164.

Cha JJ, Greenamyre JT, Nielsen EO, Penney JB, Young AB (1988) Properties of quisqualate sensitive $\mathrm{L}-\left[{ }^{3} \mathrm{H}\right]$ glutamate binding sites in rat brain as determined by quantitative autoradiography. J Neurochem 51:469-478.

Chung SH, Bliss TVP, Keating MJ (1974) The synaptic organization of optic afferents in the amphibian tectum. Proc R Soc Lond [Biol] $187: 421-447$.

Cline HT, Constantine-Paton M (1989) NMDA receptor antagonists disrupt the retinotcctal topographic map. Neuron 3:413-426.

Cline HT, Constantine-Paton M (1990) NMDA receptor agonist and antagonists alter retinal ganglion cell arbor structure in the developing frog retinotectal projection. J Neurosci 10:1197-1216.

Cline HT, Debski EA, Constantine-Paton M (1987) NMDA receptor antagonist desegregates eye-specific stripes. Proc Natl Acad Sci USA $84: 4342-4345$

Cline HT, Debski EA, Constantine-Paton M (1990) The role of the NMDA receptor in the development of the frog visual system. In: Advances in experimental medicine and biology (Ben-Ari Y, ed), pp 197-203. New York: Plenum.

Collingridge GL, Bliss TVP (1987) NMDA-receptors-their role in long-term potentiation. Trends Neurosci 10:288-293.

Collingridge GL, Kehl SJ, McLennan H (1983) The action of an $\mathrm{N}$-methylaspartate antagonist on synaptic processes in the rat hippocampus. J Physiol (Lond) 338:27P.

Constantine-Paton M (1982) The retinotectal hookup: the process of neural mapping. In: Developmental order: its origin and regulation (Subtelny S, ed), pp 317-349. New York: Liss.

Constantine-Paton M, Law MI (1978) Eye-specific termination bands in tecta of three-eyed frogs. Science 202:178-195.

Constantine-Paton M, Cline HT, Debski EA (1990) Patterned activity, synaptic convergence and the NMDA receptor in developing visual pathways. Annu Rev Neurosci 13:129-154.

Cuénod M, Streit $P$ (1979) Amino acid transmitters and local circuitry in optic tectum. In: The neurosciences, fourth study program (Schmitt FO, Worden FG, eds), pp 989-1004. Cambridge, MA: MIT Press.

Cynader M (1982) Competitive neuronal interactions underlying amblyopia. Hum Neurobiol 1:35-39.

Cynader M (1983) Prolonged sensitivity to monocular deprivation in dark-reared cats: effects of age and visual exposure. Dev Brain Res 8:155-164.

Debski EA, Constantine-Paton M (1988) The effects of glutamate receptor agonists and antagonists on the evoked tectal potential in Rana pipiens. Soc Neurosci Abstr 14:674.

Debski EA, Constantine-Paton M (1990) Evoked pre- and post-synaptic activity in the optic tectum of the cannulated tadpole. J Comp Physiol 167:377-390.

Debski EA, Cline HT, Constantine-Paton M (1987) Kynurenic acid blocks retinal-tectal transmission in Rana pipiens. Soc Neurosci Abstr 13:1691.

Debski EA, Cline HT, Constantine-Paton M (1989) Chronic application of NMDA or AP5 affects the NMDA sensitivity of the evoked tectal response in Rana pipiens. Soc Neurosci Abstr 15:495.

Debski EA, Cline HT, Constantine-Paton M (1990) Activity-dependent tuning and the NMDA receptor. J Neurobiol 21:18-32.

Fite KV, Scalia F (1976) Central visual pathways in the frog. In: The amphibian visual system: a multidisciplinary approach (Fite KV, ed), pp 87-118. New York: Academic.

Fox BES, Fraser SE (1987) Excitatory amino acids in the retino-tectal system of Xenopus laevis. Soc Neurosci Abstr 13:766.

Fox K, Daw N, Sato H (1989a) Plasticity in adult and adolescent cat visual cortex. Soc Neurosci Abstr 15:796.

Fox K, Sato H, Daw N (1989b) The location and function of NMDA receptors in cat and kitten visual cortex. J Neurosci 9:2443-2454.

Fox K, Sato H, Daw N, Czepita D (1991) Dark-rearing kittens delays the loss of NMDA-receptor function in kitten visual cortex. Nature 350:342-344.

Ginsberg KS, Johansen JA, Levine MW (1984) Common noise in the firing of neighboring ganglion cells in goldfish retina. J Physiol (Lond) 351:433-444.
Greenamyre JT, Olson JMM, Penney JB, Young AB (1985) Autoradiographic characterization of $N$-methyl-D-aspartate-, quisqualate-, and kainate-sensitive glutamate binding sites. J Pharmacol Exp Ther 233:254-263.

Gustafsson B, Wigstrom H (1988) Physiological mechanisms underlying long-term potentiation. Trends Neurosci 11:156-162.

Hickmott PW, Constantine-Paton M (1990) Physiology and morphology of neurons in Rana pipiens tectal slices. Soc Neurosci Abstr 16:985.

Johnson JW, Ascher P (1987) Glycine potentiates the NMDA response in cultured mouse brain neurons. Nature 325:529-531.

Karamian AI, Vesselkin NP, Belekhova MG, Zagorulko TM (1966) Electrophysiological characteristics of tectal and thalamo-cortical divisions of the visual system in lower vertebrates. J Comp Neurol 127 559-576.

Langdon RB, Freeman JA (1986) Antagonists of glutaminergic neurotransmission block retinotectal transmission in goldfish. Brain Res 398:169-174.

Law MI, Constantine-Paton M (1981) Anatomy and physiology of experimentally produced striped tecta. J Neurosci 1:741-759.

LeVay S, Stryker MP, Shatz CJ (1978) Ocular dominance columns and their development in layer IV of the cat's visual cortex. J Comp Neurol 179:223-244.

MacDonald JF, Mody I, Salter MW (1989) Regulation of $N$-methylD-aspartate receptors revealed by intracellular dialysis of murine neurones in culture. J Physiol (Lond) 414:17-34.

Mastronarde DN (1983a) Correlated firing of cat retinal ganglion cells. I. Spontaneously active inputs to X- and Y-cells. J Neurophysiol 49: 303-324.

Mastronarde DN (1983b) Interactions between ganglion cells in cat retina. J Neurophysiol 49:350-365.

Mayer ML, Westbrook GL, Guthrie PB (1984) Voltage-dependent block by $\mathrm{Mg}^{2+}$ of NMDA responses in spinal cord neurones. Nature 309:261-263.

Mayer ML, Vyklicky L Jr, Clements J (1989) Regulation of NMDA receptor desensitization in mouse hippocampal neurons by glycine. Nature 338:425-427.

McDonald JW, Cline HT, Constantine-Paton M, Maragos WE, Johnston MV, Young AB (1989) Quantitative autoradiographic localization of NMDA, quisqualate and PCP receptors in the frog tectum. Brain Res 482:155-159.

McDonald JW, Johnston MV (1990a) Physiological and pathophysiological roles of excitatory amino acids during central nervous system development. Brain Res Rev 15:41-70.

McDonald JW, Silverstein FS, Johnston MV (1990b) MK-801 pretreatment enhances the NMDA-mediated brain injury and increases brain NMDA recognition site binding in rats. Neuroscience 38:103113.

Meyer RL (1982) Tetrodotoxin blocks the formation of ocular dominance columns in goldfish. Science 218:589-591.

Meyer RL (1983) Tetrodotoxin inhibits the formation of refined retinotopography in goldfish. Dev Brain Res 6:293-298.

Nistri A, Sivilotti L (1985) An unusual effect of gamma-aminobutyric acid on synaptic transmission of frog tectal ncurones in vitro. $\mathrm{Br} \mathrm{J}$ Pharmacol 85:917-921.

Nowak L, Bregestovski P, Ascher P, Herbet A, Prochiantz A (1984) Magnesium gates glutamate-activated channels in mouse central neurones. Nature 307:462-465.

O'Rourke NA, Fraser SE (1986) Dynamic aspects of retinotectal map formation revealed by a vital-dye fiber-tracing technique. Dev Biol 114:265-276.

Pan HS, Frey KA, Young AB, Penney JB (1983) Changes in $\left[{ }^{3} \mathrm{H}\right]$ muscimol binding in substantia nigra, entopeduncular nucleus, globus pallidus, and thalamus after striatal lesions as demonstrated by quantitative receptor autoradiography. J Neurosci 3:1189-1198.

Reh TA, Constantine-Paton M (1984) Retinal ganglion cell terminals change their projection sites during larval development of Rana pipiens. J Neurosci 4:442-457.

Reh TA, Constantine-Paton M (1985) Eye-specific segregation requires neural activity in three-eyed Rana pipiens. $\mathrm{J}$ Neurosci 5:11321143.

Reynolds JN, Baskys A, Carlen PL (1988) The effects of serotonin on $N$-methyl-D-aspartate and synaptically evoked depolarizations in rat neocortical neurons. Brain Res 456:286-292.

Roberts PJ, Yates RA (1976) Tectal deafferentation in the frog: se- 
lective loss of L-glutamate and gamma-aminobutyrate. Neuroscience 1:371-374.

Sah DWY (1988) Potentiation of glutamate currents by VIP in cultured cortical neurons. Biophys J 53:356a.

Sakaguchi DS, Murphey RK (1985) Map formation in the developing Xenopus retinotectal system: an examination of ganglion cell terminal arborizations. J Neurosci 5:3228-3245.

Scherer WJ, Udin SB (1989) $N$-methyl-D-aspartate antagonists prevent interaction of binocular maps in Xenopus tectum. J Neurosci 9: $3837-3843$.

Schmidt JT (1990) Long-term potentiation and activity-dependent retinotopic sharpening in the regenerating retinotectal projection of goldfish: common sensitive period and sensitivity to NMDA blockers. J Neurosci 10:233-246.

Silberstein GB, Daniel CW (1982) Flvax 40P implants: sustained, local release of bioactive molecules influencing mammary ductal development. Dev Biol 93:272-278.

Sperry RW (1963) Chemoaffinity in the orderly growth of nerve fiber patterns and connections. Proc Natl Acad Sci USA 50:703-710.

Stone TW, Burton NR (1988) NMDA receptors and ligands in the vertebrate CNS. Prog Neurobiol 30:333-368.

Stuermer CAO (1988) Retinotopic organization of the developing retinotectal projection in the zebrafish embryo. J Neurosci 8:4513-4530.
Székely G, Lázár G (1976) Cellular and synaptic architecture of the optic tectum. In: Frog neurobiology (Llinás R, Precht W, eds), pp 407-434. New York: Springer.

Taylor AC, Kollros JJ (1946) Stages in the normal development of Rana pipiens larvae. Anat Rec 94:7-23.

Trussell LO, Thio LL, Zorumski CF, Fischbach GD (1988) Rapid desensitization of glutamate receptors in vertebrate central neurons. Proc Natl Acad Sci USA 85:2834-2838.

Uckele J, McDonald JW, O'Mara K, Silverstein FS, Johnson MV (1989) Chronic MK-80 I treatment enhances NMDA recognition site binding in perinatal rats. Soc Neurosci Abstr 15:198.

Udin SB, Fawcett JW (1988) Formation of topographic maps. Annu Rev Neurosci 11:289-327.

Vielmeyer J, Steurmer CAO (1989) Goldfish retinal axons respond to position-specific properties of tectal cell membranes in vitro. Neuron 2:1331-1339.

Walter J, Kern-Veits B, Huf J, Stolze B, Bonhoeffer F (1987) Recognition of position-specific properties of tectal cell membranes by retinal axons in vitro. Development 101:685-696.

Whitelaw VA, Cowan JD (1981) Specificity and plasticity of retinotectal connections: a computational model. J Neurosci 1:1369-1387. 